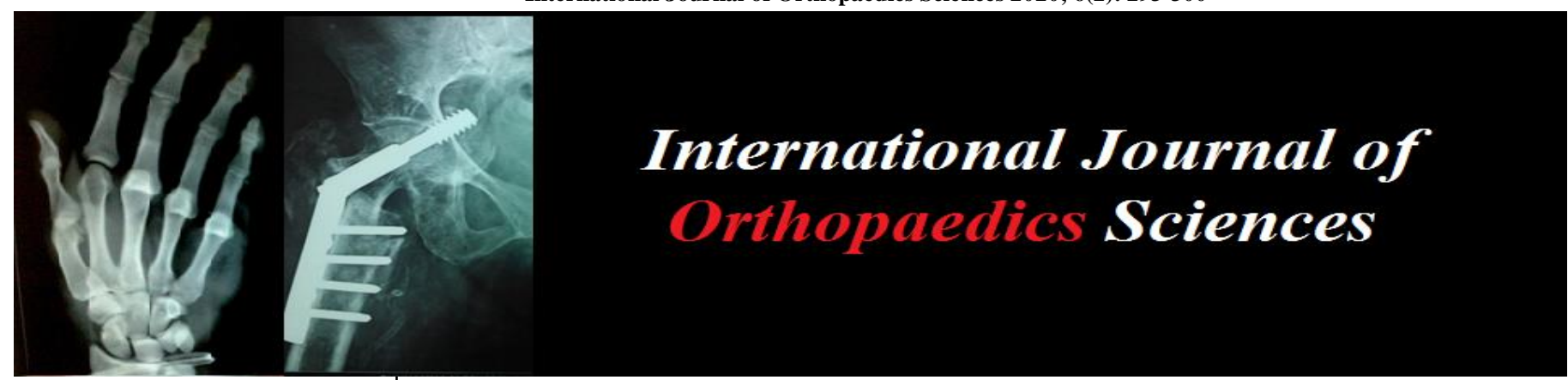

E-ISSN: 2395-1958

P-ISSN: 2706-6630

IJOS 2020; 6(2): 293-300

(C) 2020 IJOS

www.orthopaper.com

Received: 18-02-2020

Accepted: 20-03-2020

Dr. Ahamad Shaheel Sultan Senior Resident, Govt. T.D Medical College Alappuzha, Kerala University of Health Sciences (KHUS), Kerala, India

Dr. Bindulal VA

Assistant Professor, Govt. T.D Medical College Alappuzha, Kerala University of Health Sciences (KHUS), Kerala, India

Corresponding Author: Dr. Bindulal VA Assistant Professor, Govt. T.D Medical College Alappuzha, Kerala University of Health Sciences (KHUS), Kerala, India

\section{Functional \& radiological outcome of treatment of clavicle- conservative versus open reduction internal fixation}

\section{Dr. Ahamad Shaheel Sultan and Dr. Bindulal VA}

DOI: https://doi.org/10.22271/ortho.2020.v6.i2e.2053

\section{Abstract}

Midshaft clavicular fractures have traditionally been treated nonoperatively. Prevalence of non-union or mal-union in displaced midshaft clavicular fractures after conservative treatment is higher as compared to those treated with open reduction and internal fixation. Surgery is believed to be the primary treatment for displaced midshaft clavicular fractures. Operative fixation of the clavicle fractures result in improved function, shorter time for union and early return to activity as compared to those treated conservatively.

Objectives: The objective of the study was to compare the functional \& radiological outcome of open reduction and internal fixation of clavicle with conservative management.

Materials and methods: A prospective study was conducted at Department of Orthopaedics, Govt. TD Medical College Hospital for 2 years. In this study period 100 cases of midshaft clavicle fractures, treated by operative and non-operative methods (50 patients each treated by operative and non-operative methods). All the patients in this study were asked to follow up at 6,12 and 24 weeks. The patients were evaluated both clinically and radiologically.

Clinical evaluation was done based on Constant- Murley and DASH score.

Results: Males outnumbered females by 66\% (i.e. 83\% against 17\%). Among 100 patients, 54 patients (54\%) had RTA while the remaining 46 patients $(46 \%)$ had a history of fall. The youngest patient was $19 y$ rs and the oldest was 72 yrs old. Mean age was 36.93 years. Complications included plate breakage in 1 patient, nonunion in 13 patients and restriction of range of motion in 18 patients were seen. Constant and Murley scoring system showed, out of 50 patients conservatively treated, 23 patients $(46 \%)$ fell under Good category, 18 patients $(36 \%)$ had Fair functional outcome while 9 patient $(18 \%)$ had Poor outcome. In the Operative group, out of 50 patients, 41 patients $(82 \%)$ fell under Good category, 8 patients (16\%) had Fair functional outcome while 1 patient (2\%) had Poor outcome.

Conclusion: We conclude that midshaft clavicular fractures treated operatively had a better functional outcome as compared to those treated conservatively.

Keywords: Clavicle fracture, operative, non-operative, constant-murley \& DASH score

\section{Introduction}

Clavicle fractures are common injuries and account for $\sim 2.6-5 \%$ of all the fractures in adults $[1,2]$

The most common mechanism for a clavicular fracture is a fall onto the ipsilateral shoulder, making athletes particularly prone to this injury ${ }^{[3]}$.

Majority of clavicular fractures about $80-85 \%$ occur in the midshaft of the bone, where the typical compressive forces are applied to the shoulder and the narrow cross section of the bone combine and result in bony failure ${ }^{[4]}$.

The peak incidence occurs in third decade of life. Open clavicular fracture is an absolute rarity and found in only $0.1-1 \%$ of cases.

The rate of midclavicular fractures is more than twice as high as in women. About $10 \%$ of patients have significant accompanying injuries, most frequently vertebral fractures, other shoulder girdle injuries or broken ribs ${ }^{[5]}$

Traditionally, nonsurgical management has been favored as the treatment for most clavicular fractures $[6,7]$.

However, recent evidence has emerged indicating that operative fixation presents lower 
nonunion rates, better functional outcomes, improved cosmesis, and greater patient satisfaction compared with closed treatment.

Several recent prospective randomized clinical trials that compared nonoperative treatment with open reduction and internal fixation with plate fixation showed that operative In our study as per the Constant and Murley scoring system, In conservative study, Out of 50 patients, 23 patients (46\%) fell under Good category, 18 patients $(36 \%)$ had Fair functional outcome while 9 patient (18\%) had Poor outcome.

\section{Aims and objectives}

The objective of the study was to compare the functional \& radiological outcome of open reduction and internal fixation of clavicle with conservative management.

\section{Materials and methodology \\ Methodology \\ Study design}

It is a prospective study, 100 patients presenting to casualty and outpatient clinic of Department of Orthopedics, Government TD Medical College, and Alappuzha with midthird clavicle fractures between August 2016 and August 2018 were included out of which 50 were treated conservatively \& other 50 by open reduction \& internal fixation. Patients with open fracture, medial \& lateral third fractures, having neurovascular injuries, pathological fractures, acromio- clavicular joint injuries, multiple fractures or other associated fractures were excluded from the study. Patients were explained the purpose of the study and a separate informed written consent for being included in the study was obtained from them. The study was approved by the Institutional Ethics Committee.

\section{Treatment protocol}

Thorough Clinical and physical examination carried out for all the patients.

$\mathrm{X}$-ray-Clavicle with Shoulder AP view taken.

1. Clavicle bracing done for patients under Conservative Management

2. Open Reduction \& Internal Fixation for patients in Operative Group

\section{Period of follow up}

Patients are followed up for a period of 6 weeks, 12 weeks and 24 weeks at regular intervals.

\section{Surgical technique}

\section{Anteroinferior plate and screw fixation}

- The patient is placed supine and a large bump is placed between the scapulae which allows the injured shoulder girdle to fall posteriorly and helps to restore length and thus increases the exposure of clavicle.

- Incision is made over the fracture from sternal notch to anterior edge of acromion.

Lateral platysma is released and supraclavicular nerve is identified.

- Clavipectoral fascia is incised along its attachment.
- Soft tissue dissection is carried out and the fracture is reduced and held with bone clamps.

- A lag screw is used for provisional fixation if required.

- A $3.5 \mathrm{~mm}$ plate is contoured along the anteroinferior edge of the clavicle

- The screws for plate fixation are aimed posteriorly and superiorly ${ }^{[8]}$.

\section{A. Superior fixation}

- The plate is contoured along the superior edge of the clavicle.

- The screws are inserted from superior to inferior.

- Care must be taken to avoid injury to the neurovascular structures ${ }^{[8]}$.

\section{Rehabilitation}

Rehabilitation protocol

i) Day one to one week: Limb is immobilized in a sling with shoulder held in adduction and internal rotation. Elbow is maintained at $90^{\circ}$ of flexion with no range of motion at shoulder.

ii) At two weeks: After suture removal gentle pendulum exercises to the shoulder in the sling as pain permits is allowed.

iii) At four to six weeks: At the end of 6 weeks gentle active range of motion of the shoulder is allowed. Abduction is limited to $80^{\circ}$.

iv) At six to eight weeks: Active to active - assistive range of motion in all planes are allowed.

v) At eight to 12 weeks: Isometric and isotonic exercises are pre

vi) Scribed to the shoulder girdle muscles ${ }^{[8]}$.

\section{Parameters used}

Patients will be evaluated both clinically and radiologically. Clinical evaluation by using:

Table 3: Constant Murley Score

\begin{tabular}{|c|c|}
\hline Criteria & Maximum Score \\
\hline Pain & 15 \\
\hline Activities of daily living & 20 \\
\hline Range of motion & 40 \\
\hline Strength & 25 \\
\hline Total & 100 \\
\hline
\end{tabular}

The dash score (disabilities of arm, shoulder and hand)

Radiographs of the immediate post-operative period compared with that of latest follow up. The union of fracture will be assessed by callus formation and disappearance of fracture line.

\section{Statistical analysis}

Collected data was entered in MS Excel 2010 and analysed using SPSS version 20. The results were expressed in percentages and represented with charts and tables which was generated using MS Word and MS Excel. Chi square test, ANOVA test etc. were used to find the association between the study variables

\section{Observations and results}

Table 4: Age Distribution of Patients Studied

\begin{tabular}{|c|c|c|c|c|}
\hline Age in Years & No of Patients & \% & Mean Age (Years) & Standard Deviation \\
\hline$<20$ & 3 & $3 \%$ & 36.93 & 11.78 \\
\hline $21-30$ & 35 & $35 \%$ & & \\
\hline
\end{tabular}




\begin{tabular}{|c|c|c|}
\hline $31-40$ & 29 & $29 \%$ \\
\hline $41-50$ & 20 & $20 \%$ \\
\hline $51-60$ & 8 & $8 \%$ \\
\hline $61-70$ & 4 & $4 \%$ \\
\hline $71-80$ & 1 & $1 \%$ \\
\hline Total & 100 & \\
\hline
\end{tabular}

$\mathrm{x}^{2}=8.901 \mathrm{p}=0.113$



Fig 15: Age group of study subjects in years

In this study we have included patients ranging from the age of 19-80. Among them we had the highest number of patients in the age group of $21-30$ years $(35 \%)$. The mean age was 36.9 years with the standard deviation being 11.78 .

Table 5: Gender distribution of Patients studied

\begin{tabular}{|c|c|c|}
\hline Gender & No of Patients & \% \\
\hline Female & 17 & 17 \\
\hline Male & 83 & 83 \\
\hline Total & 100 & 100 \\
\hline
\end{tabular}

$\mathrm{x}^{2}=1.772 \mathrm{p}=0.183 \mathrm{~ns}$

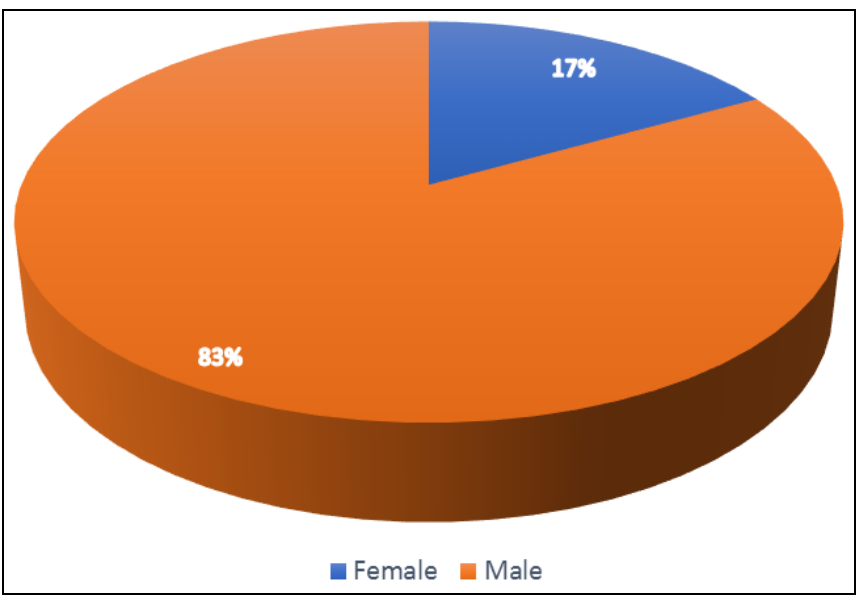

Fig 16: Distribution of subjects according to Gender

In the present study among 100 patients, $83(83 \%)$ were males and $17(17 \%)$ were

Females.

Table 6: Mode of Injury distribution of the patients studied

\begin{tabular}{|c|c|c|}
\hline Mode of Injury & No of Patients & \% \\
\hline RTA & 54 & $54 \%$ \\
\hline Fall & 46 & $46 \%$ \\
\hline Total & 100 & $100 \%$ \\
\hline
\end{tabular}

$\mathrm{x}^{2}=1.772 \mathrm{p}=0.183 \mathrm{~ns}$

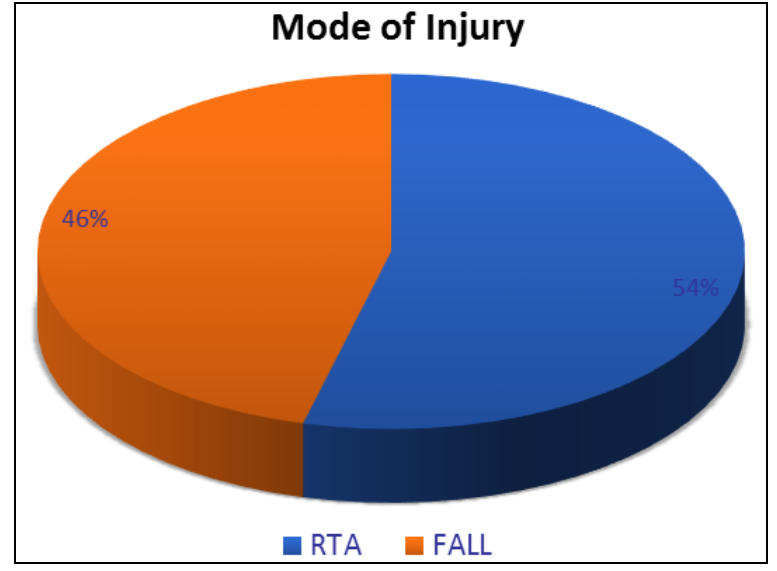

Fig 17: Distribution of subjects according to mode of injury

In our study the mode of injury because of RTA and fall constituted $54 \%$ and $46 \%$ respectively.

Table 7: Side affected of the patients

\begin{tabular}{|c|c|}
\hline Side Affected & Number (\%) \\
\hline Left & $37(37 \%)$ \\
\hline Right & $63(63 \%)$ \\
\hline Total & $100(100 \%)$ \\
\hline $\mathrm{X}^{2}=2.102 \mathrm{p}=0.147 \mathrm{~ns}$ &
\end{tabular}

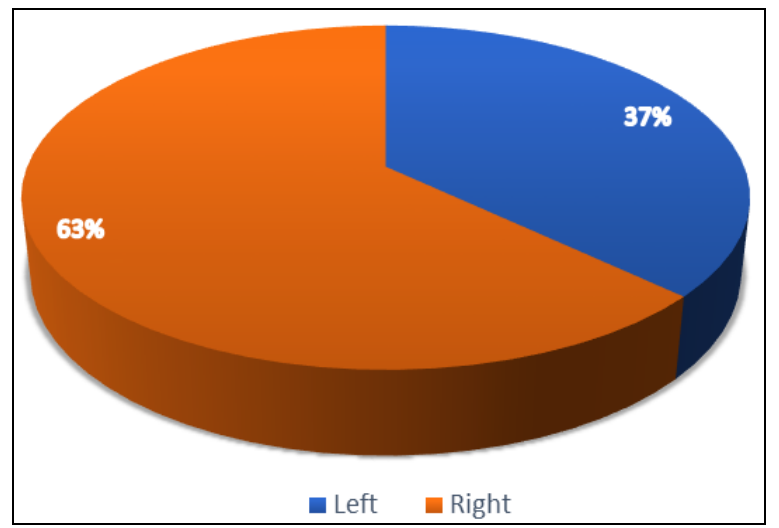

Fig 18: Distribution of study subjects according to side of injury 
In our study left sided fracture was noted in 37 patients (37\%) whereas 63 patients (63\%) had clavicular fractures on the right side.

\section{Conservative}

Table 8: Time of Radiological Union (in Weeks) of the Study Subjects

\begin{tabular}{|c|c|c|c|}
\hline Time of radiological union in weeks & Total & Mean & Standard Deviation \\
\hline 12 & $21(42 \%)$ & \multirow{4}{*}{17.19} & \multirow{4}{*}{6.29} \\
\hline 24 & $16(32 \%)$ & & \\
\hline Non-union & $13(26 \%)$ & & \\
\hline Total & 50 & & \\
\hline
\end{tabular}

\section{Operative}

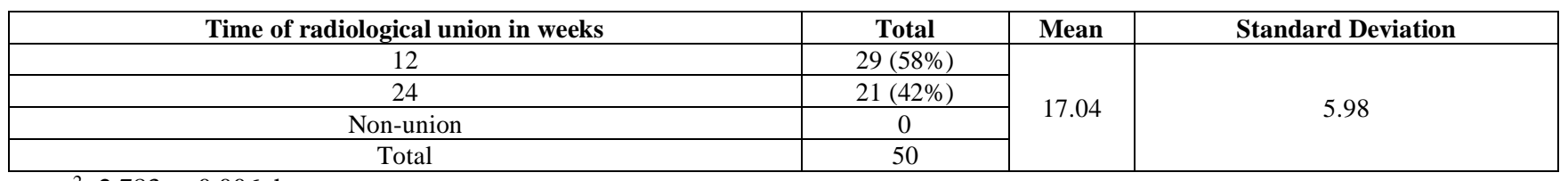

$\mathrm{x}^{2}=2.783 \mathrm{p}<0.006 \mathrm{vhs}$

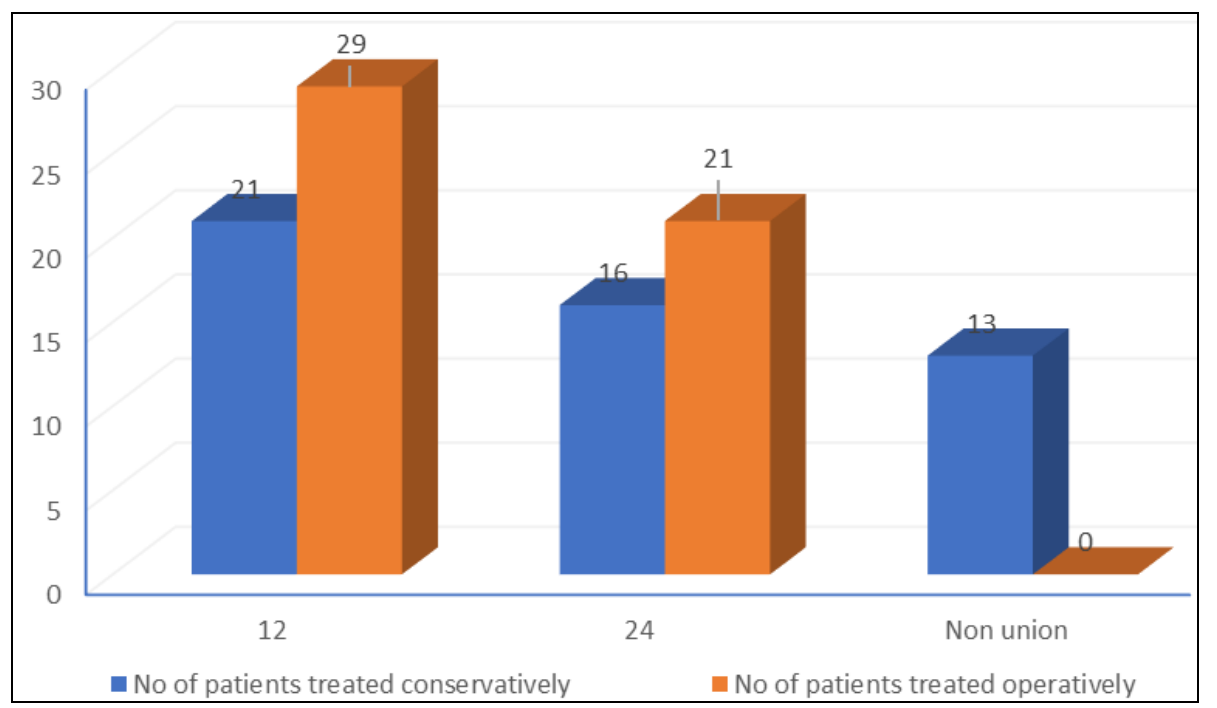

Fig: 19

In our study, in conservative method, most of the patients ie, $21(42 \%)$ of them achieved radiological union in 12 weeks and 16 patients (32\%) achieved union in 24 weeks. 13 patients $(26 \%)$ had non-union.

In our study, In Operative method, most of the patients ie, 29 $(58 \%)$ of them achieved radiological union in 12 weeks and 21 patients $(42 \%)$ achieved union in 24 weeks.

\section{Operative}

Table 9: Complications of Patients Studied

\begin{tabular}{|c|c|}
\hline Complications & Total (Out of 50) \\
\hline Infection & 0 \\
\hline Plate breakage & 1 \\
\hline Plate Prominence & 0 \\
\hline Restriction of Shoulder Movements & 4 \\
\hline Nonunion & 0 \\
\hline
\end{tabular}

\section{Conservative}

\begin{tabular}{|c|c|}
\hline Complications & Total (Out of 50) \\
\hline Restriction of Shoulder Movements & 14 \\
\hline Non-union & 13 \\
\hline
\end{tabular}

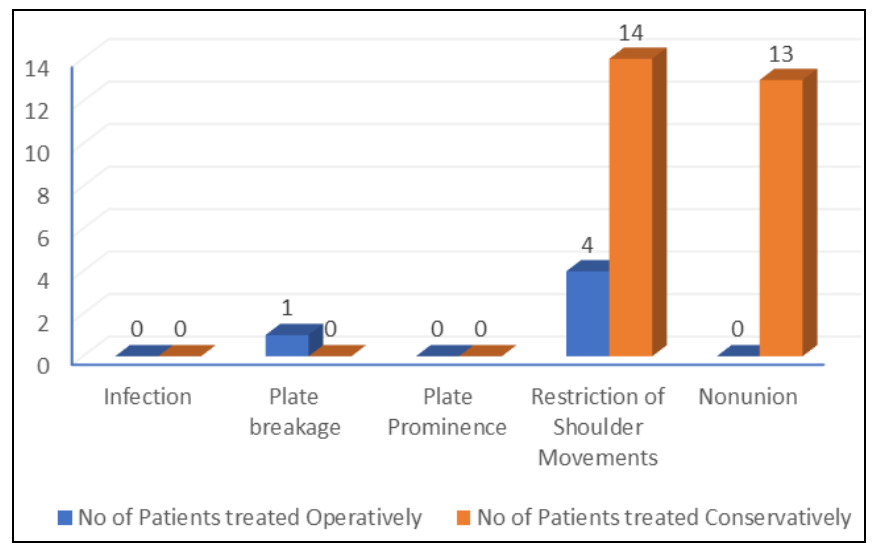

Fig: 20

In our study, In Conservative method, 5 patients had complications. Plate breakage and restriction of shoulder movements were noted in $10 \%$ of the study subjects. In Operative method, 27 patients had complications. Non union (13) and restriction of shoulder movements (14) were noted in $54 \%$ of the study subjects. 
Table 10: Duration of stay (in days) in hospital of study subjects treated operatively

\begin{tabular}{|c|c|c|c|}
\hline Duration of stay (in days) in hospital & Number of Patients & Mean & Standard Deviation \\
\hline $1-3$ & $2(4 \%)$ & \multirow{4}{*}{5.3} & \multirow{4}{*}{1.89} \\
\hline $4-6$ & $41(82 \%)$ & & \\
\hline $7-10$ & $7(14 \%)$ & & \\
\hline Total & $50(100 \%)$ & & \\
\hline
\end{tabular}

$\mathrm{x}^{2}=33.614 \mathrm{P}<0.001 \mathrm{vhs}$

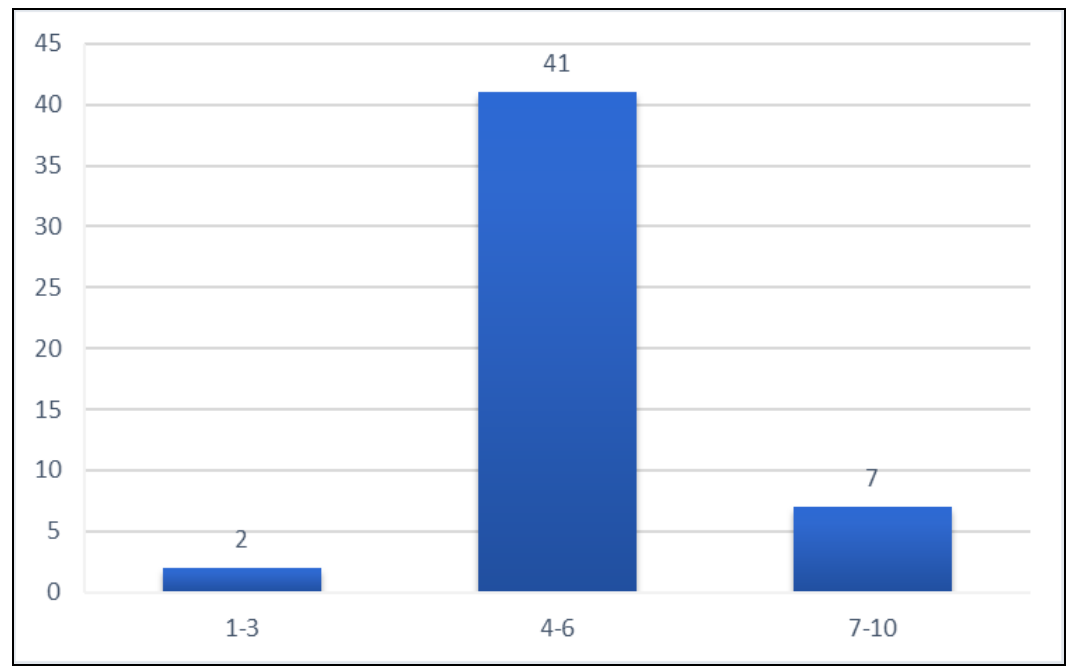

In our study, $82 \%$ of patients treated operatively had a while the remaining $14 \%$ of patients stayed for 7-10 days. hospital stay of 4-6 days, $4 \%$ of patients stayed for 1-3 days

Table 11: Functional Outcome of patients studied

\begin{tabular}{|c|c|c|}
\hline Result & Conservative & Operative \\
\hline Good & 23 & 41 \\
\hline Fair & 18 & 8 \\
\hline Poor & 9 & 1 \\
\hline Total & 50 & \\
\hline \multicolumn{2}{|c}{$\mathrm{x}^{2}=18.511 \mathrm{p}=0.001 \mathrm{vhs}$} \\
\hline
\end{tabular}

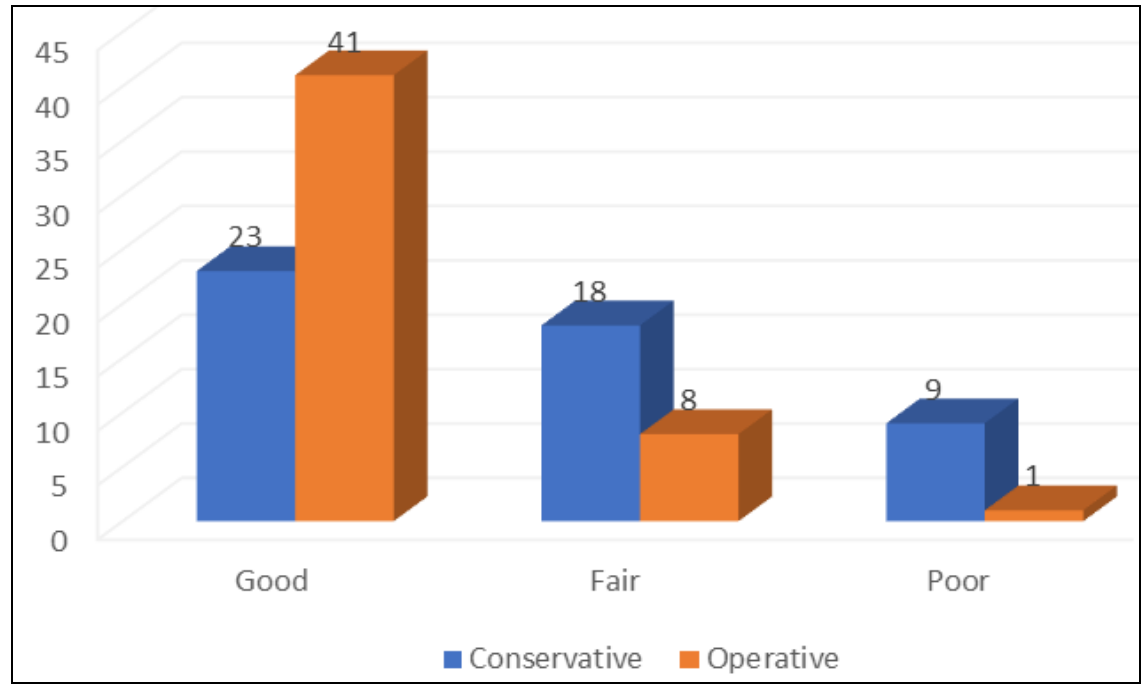

Fig: 22

In our study as per the Constant and Murley scoring system,In conservative method, 23 patients $(46 \%)$ fell under Good category, 18 patients (36\%) had Fair functional outcome while 9 patients $(18 \%)$ had Poor outcome.
In our study as per the Constant and Murley scoring system,In operative method, 41 patients $(82 \%)$ fell under Good category, 8 patients (16\%) had Fair functional outcome while 1 patient $(2 \%)$ had Poor outcome. 


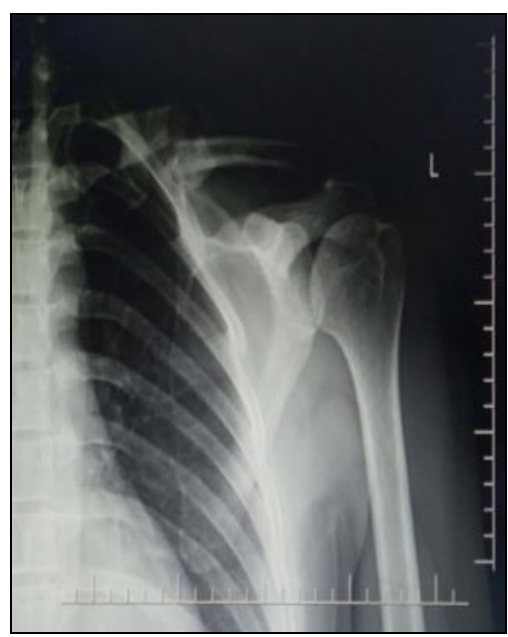

X-RAY on Admission

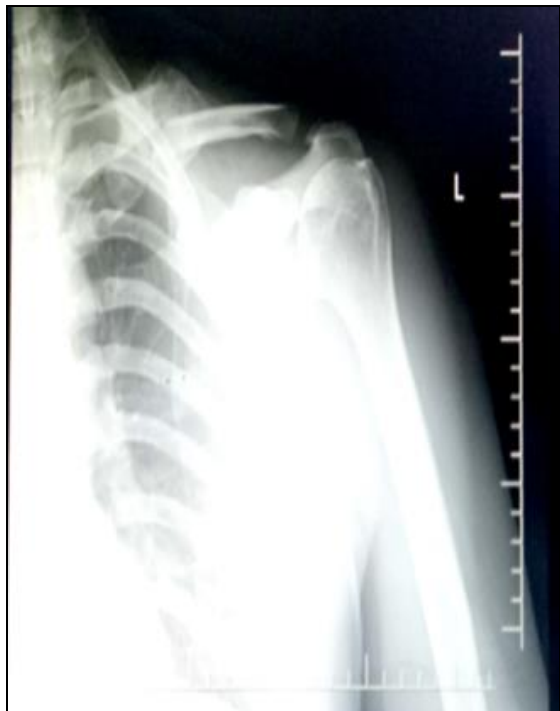

12 Weeks

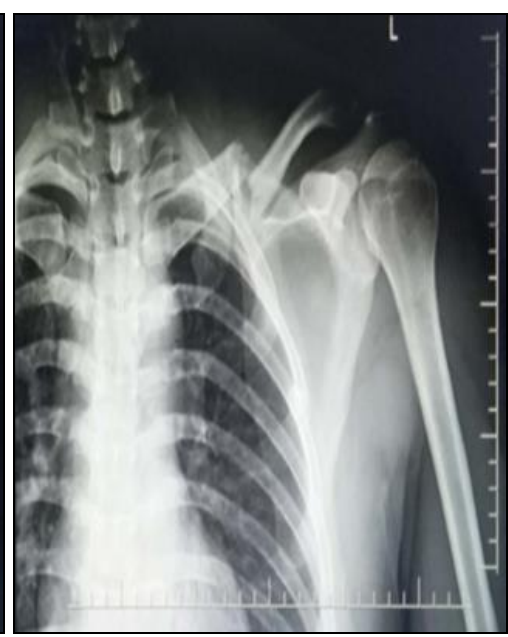

6 Weeks

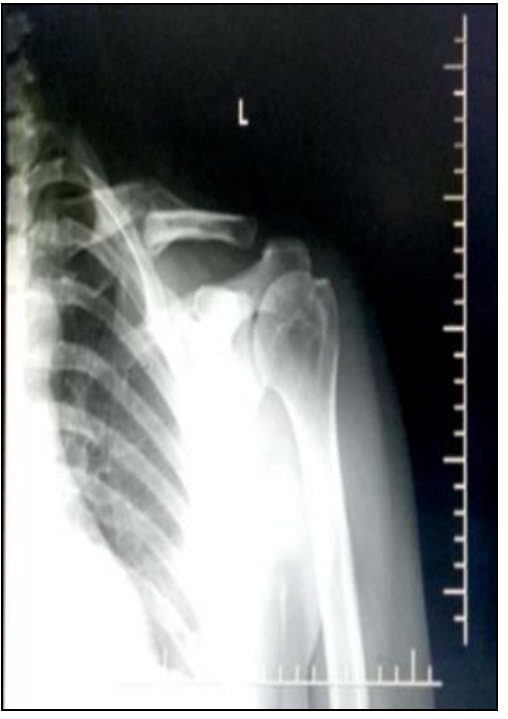

24 Weeks

Case 2: X-Rays of patient treated operatively

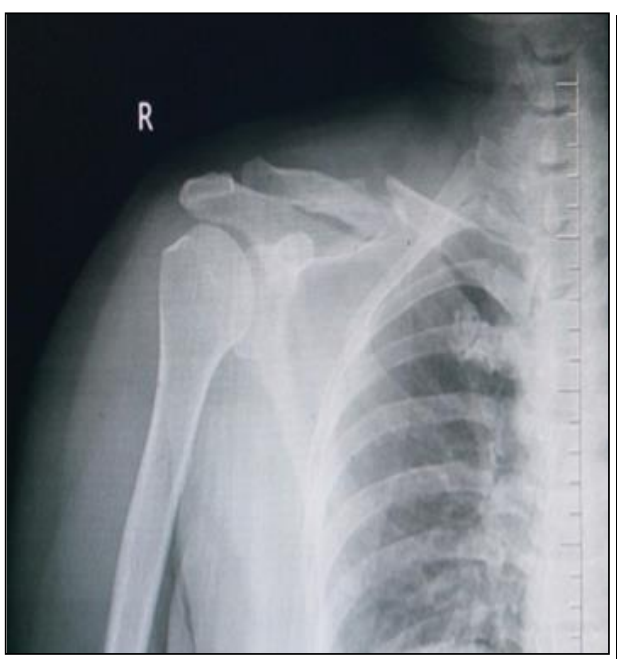

PRE-OP

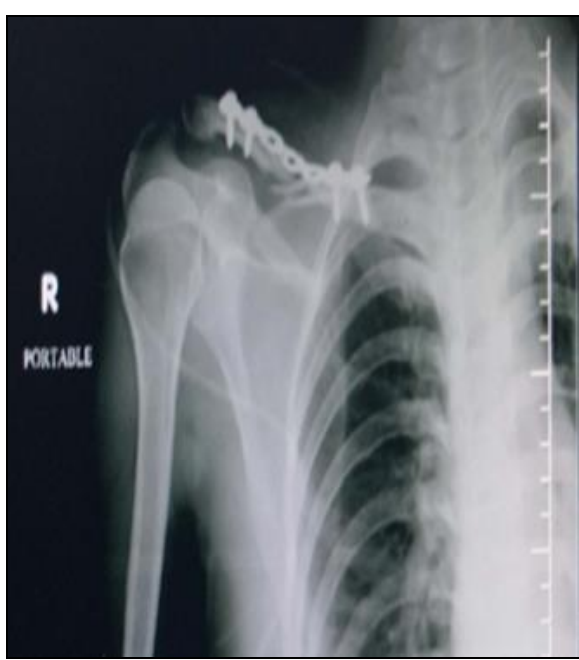

6 Weeks 


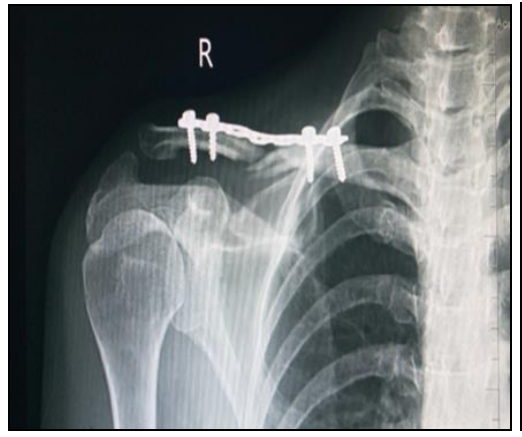

12 weeks

\section{Discussion}

\section{Age distribution of patients studied}

- In this study, patients aged more than 18 years were included. Most patients were in the age group between 21-30 years $(35 \%)$. The youngest patient was 19 years and the oldest was 72 years old. Average age was 36.93 years with standard deviation of 11.78 .

- In a similar kind of study conducted by Ram Kumar Reddy et al ${ }^{[25]}$, most were in the age group between 1939 years $(66 \%)$ while 2 patients were above the age of 50. Average age was 33.8 years.

- In a study conducted by Ramesh et al [26], among 20 patients, $45 \%$ were in the age group of 21-30 years. The youngest patient was 19 years and the oldest was 60 years old.

- In a study conducted by H. Jiang et al. ${ }^{[27]}$ mean age was 45.In a study conducted by Chanappa TS et al ${ }^{[28]}$ the mean age of the patient was 35 years and youngest being 19 years.

\section{Sex distribution}

- In the present study among 100 patients, 83 (83\%) were males and $17(17 \%)$ were females. In a study conducted by TS Chanappa et $a l^{[28]}$ male predominance was seen.

- In a similar kind of study by Fathy H. Salama et al ${ }^{[29]}$, there were 13 men $(81.25 \%)$ and 3 women $(18.75 \%)$.

- In a study conducted by Ram Kumar et al ${ }^{[25]}$, all the 30 patients were males.

- A study conducted by H. Jiang et al ${ }^{[27]}$, involved $62.5 \%$ males and $35.5 \%$ females.

\section{Mode of injury}

- In our study the mode of injury because of RTA was $54 \%$ and fall was $46 \%$.

- In a study by Ram Kumar et al. ${ }^{[25]}$ the mode of injury in $56 \%$ cases were road traffic accidents and in $44 \%$ patients it was due to a fall.

- Mohamed E. Attia et al, ${ }^{[30]}$ stated that the cause of fracture was road traffic accident in $53.3 \%$ and fall in $47.7 \%$ patients

- In the study conducted by H. Jiang et al. ${ }^{(27)}, 5078 \%$ of subjects sustained clavicular fractures due to RTA and $22 \%$ because of a fall

\section{Side affected}

In our study, right sided clavicular fracture was seen in 63 patients $(63 \%)$ while left sided clavicular fracture was seen in 37 patients $(37 \%)$.

In a study conducted by Fujita $\mathrm{K}$ et al ${ }^{[31]}$ there were 10 patients $(50 \%)$ with left sided fracture in operative group and 9 patients $(45 \%)$ in the non-operative group and 9 patients $(45 \%)$ with right sided fractures in operative group and 11

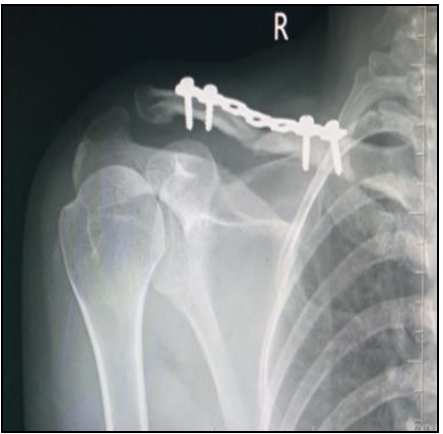

24 weeks

patients $(55 \%)$ in the non-operative group. 1 patient $(5 \%)$ had bilateral clavicle fracture in operative group. Right sided fracture predominance can be drawn from this inference.

\section{Duration of Union}

In our study, 21 patients (42\%) in the conservative group and 29 patients $(58 \%)$ in the operative group achieved radiological union at 12 weeks while 16 patients $(32 \%)$ in the conservative group and 21 patients $(42 \%)$ in the operative group achieved radiological union at 24 weeks. 13 out of 50 patients treated conservatively developed nonunion whereas none of the patients treated operatively developed non-union.

In a study conducted by TS Chanappa et al ${ }^{[28]}$ the average union time for operative group was 15.1 weeks and average union time for conservative group was 20 weeks. The difference was statically highly significant $(P<0.001)$.

\section{Complications associated with clavicular fractures}

- In our study we came across complications like plate breakage in 1 patient, non- union in 13 patients and restriction of range of motion in 18 patients.

- In this study 14 patients experienced restriction of shoulder movements which resulted in difficulty to perform daily routine activities. In a study conducted by H. Jiang et al. ${ }^{[27]}$ the complications were around $56 \%$. $\mathrm{He}$ encountered dysesthesia in the area of incision in 10 patients, hypertrophic scarring in 5, painful shoulder in 2 and limitation of shoulder movements in 1 case among 32 patients studied.

\section{Plate breakage}

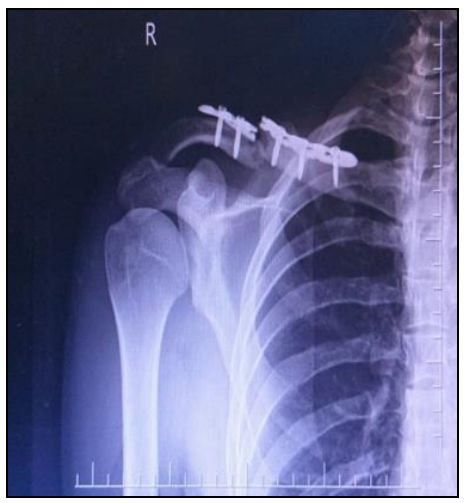

Fig: 23

In our study (1\%) a 25-year-old male presented in the OPD with a complaint of severe pain after lifting heavy object over the right shoulder. He gives history of being operated as a study subject

- One month back: On further investigation, the x-ray of 
clavicle showed plate breakage. Plate was removed and replating was done as the fracture was not united.

- Non-union: In this study non-union was seen in 13 patients. Neer reported non-union in only three of 2235 patients with middle third fractures treated by closed methods ${ }^{[10]}$. while Rowe reported non-union in four of 566 clavicular fractures ${ }^{[11]}$.

Functional outcome of midshaft clavicular fractures treated conservatively and with open reduction and internal fixation (ORIF).

In this study as per Constant and Murley scoring system, of the 50 patients treated conservatively, 23 patients showed good, 18 of them showed fair and 9 of them showed poor functional outcome. Out of the remaining 50 patients who were treated with open reduction and internal fixation (ORIF), 41 patients showed good, 8 of them showed fair and 1 of them showed poor functional outcome.

\section{Conclusion}

We observed that early primary plate fixation of midshaft clavicle fractures led to improved patient-oriented outcomes and earlier return to function.

\section{References}

1. Postacchini F, Gumina S, De Santis P, Albo F. Epidemiology of clavicle fractures. J Shoulder Elbow Surg. 2002; 11:452-456.

2. Robinson CM. Fractures of the clavicle in the adult. Epidemiology and classification. J Bone Joint Surg Br. 1998; 80:476-484.

3. Stanley D, Trowbridge EA, Norris SH. The mechanism of clavicular fracture. A clinical and biomechanical analysis. J Bone Joint Surg Br. 1988; 70:461-464.

4. Court-Brown CM, D HJ, McQueen MM, M RW, PAUL T 111, editors. Rockwood and green's fractures in adults. In: walters kluwer. $8^{\text {th }}$ edition. PHILADELPHIA: Wolter Kluwer, 2015, 1644.

5. Schiffer G, Faymonville C, Skouras E, Andermahr J, Jubel A. Midclavicular fracture: not just a trivial injury: current treatment options. Dtsch Arztebl Int. 2010; 107(41);711-7.

6. Ranalletta M, Rossi LA, Piuzzi NS, Bertona A, Bongiovanni SL, Maignon G. Return to sports after plate fixation of displaced midshaft clavicular fractures in athletes. Am J Sports Med. 2015; 43:565-569.

7. Verborgt O, Pittoors K, Van Glabbeek F, Declercq G, Nuyts R, Somville J. Plate fixation of middle-third fractures of the clavicle in the semi-professional athlete. Acta Orthop Belg. 2005; 71:17-21.

8. M Azar F, H BJ, S Canale T. Editors. Campbell's operative orthopaedics. $13^{\text {th }}$ edition. Philadelphia: Elsevier, 3, 2928-2930.

9. Gaudinez RF, Hoppenfeld S. Clavicle fractures. Chapter10 In: Hoppenfeld S, Murthy VL, editors. Treatment and Rehabilitation of fractures, Philadelphia: Lippincott Williams and Wilkins, 2000, 73-84.

10. Nicholl EA. Annotation. Miners and mannequins. J Bone Joint Surgery (Br). 1954; 36:171-172.

11. Neer CS. Nonunion of the clavicle. JAMA, 1960; 172:1006-1011.

12. Rowe CR. An atlas of anatomy and treatment of midclavicular fractures. Clin. Orthop. 1968; 58:29-42.

13. Ali Khan MA, Lucas HK. Plating of fractures of the middle third of the Clavicle. Injury. 1977; 9:263-267.

14. Manske DJ, Szabo RM. The operative treatment of mid shaft clavicular nonunion. J Bone Joint Surgery (Am), 1985; 67:1367-1371.

15. Poingenfurst J, Reiler T, Fischer W. Plating of fresh clavicular fractures. Experience with 60 operations. Unfallchirurgie. 1988; 14:26-37.

16. Connolly JF, Dehne R. Non-Union of the clavicle and thoracic outlet Syndrome. J Trauma. 1989; 29:11271132.

17. Schwarz N, Hocker K. Osteosynthesis of irreducible fractures of the clavicle with $2.7 \mathrm{~mm}$ ASIF plate. J Trauma. 1992; 33:179-183.

18. Bostman O, Manninen M, Pihlajamaki H. Complications of plate fixation in fresh displaced mid clavicular fractures. J Trauma. 1997; 43:778-783.

19. Shen WJ, Liu TJ, Shen YS. Plate fixation of fresh displaced mid shaft clavicle fractures. Injury. 2000; 31(3):175-179.

20. Iannotti MR, Crosby LA, Stafford P, Grayson G, Goulet R. Effects of plate location and selection on the stability of mid shaft clavicle osteotomies : a biomechanical study. J Shoulder Elbow surgery. 2002; 11(5):457-462.

21. Huang JI, Toogood P, Chen MR, Wilber JH, Cooperman DR. Clavicular anatomy and the applicability of precontoured plates. J Bone Joint Surg Am. 2007; 89:2260-5.

22. Kulshrestha V. Primary Plating Of Displaced Mid-Shaft Clavicular Fractures. MJAFI. 2008; 64:208-11.

23. Wun-Jer Shen MD, Tsung-Jen Liu MD, Young-Shung Shen MD. Po Cheng Orthopaedic Institute, 100 Po-Ai 2nd Road, Kaohsiung, 813, Taiwan. Plate Fixation of Fresh Displaced Midshaft Clavicle Fractures, J Bone Joint Surg [Br]. 2008; 90-B:1495-B.

24. Chul-Hyun Cho, MD, Kwang-Soon Song, MD, ByungWoo Min, MD, Ki Cheor Bae, MD, Kyung-Jae Lee, MD. Reconstruction Plate versus Reconstruction Locking Compression Plate for Clavicle Fractures. Clinics in Orthopedic Surgery. 2010: 2:154-59.

25. Darren S, Drosdowech MD, Frcsc. Biomechanical Analysis Of Fixation Of Middle Third Fractures Of Clavicle, Journal Of Ortopaedic Trauma. 2011; 25(1):3943.

26. Reddy RK, Rathod J, Rao KT. A Study on Surgical Management of Clavicle Midshaft Fractures by Locking Plate. IJCMR. 2016: 3(7):2005-7.

27. Ramesh et al. Functional outcome of displaced middle third clavicle fractures treated by precontoured locking plate. IJSR. 2016; 5(3):731-733.

28. Jiang $\mathrm{H}$ et al; Operative treatment of clavicle midshaft fractures using a locking compression plate

29. Comparison between mini-invasive plate osteosynthesis (MIPPO) technique and conventional open reduction.

30. Dr. Channappa TS, Dr. Radhakrishna AM, Dr. Sumanth B, Dr. Shivakumar HB. A comparative study of functional outcome of clavicular fractures treated by operative and nonoperative methods. IJOS 2017; 3(1):509-514.

31. Fathy H, Salama. Surgical treatment of acute displaced midshaft clavicular fractures with plates: Egyptian journal of orthopaedics; September. 2016; 30:70-8.

32. Mohamed EA, Amr I, Zanfaly. Plate fixation in midshaft fracture clavicle. Egyptian Orthopedic Journal. 2014; 49:299-303.

33. Fujita K, Matsuda K, Sakai Y, Sakai H, Mizuno K. Late thoracic outlet syndrome secondary to malunion of the fractured clavicle: case report and review of the literature. J Trauma. 2001; 50:332-5. 